\title{
AMBIÊNCIAS AFETIVAS EM AMOR À FLOR DA PELE DE W. KAR WAI
}

\section{AFFECTS AND MOODS IN W. KAR WAI'S IN THE MOOD FOR LOVE}

Adalberto Müller Universidade Federal Fluminense

\section{Resumo}

A partir do conceito de Stimmung elaborado por Gumbrecht (2010), é analisado o filme Amor à flor da pele (2000), para demonstrar que o essencial desse filme está na articulação entre as ambiências afetivas e a História.

Palavras-chave: Stimmung; Kar Wai; Ambiência; Afetos

\begin{abstract}
Based on Gumbrecht's (2010) concept of Stimmung, is analyzed the film In the mood for love (2000) in order to demonstrate that the essential in this film lies in the way it articulates affective moods and History.
\end{abstract}

Keywords: Stimmung; Kar Wai; Mood; Affects 
Revejo In the mood for love/Amor à flor da pele onze anos depois de seu lançamento no Brasil, e no mesmo momento me vêm à lembrança mais uma vez uma aquela decantada e encantada reflexão de Andrei Tarkovski (1989), segundo o qual a imagem cinematográfica não deveria deveria ser um mero "efeito" (como teorizava Lev Kuleshov), e muito menos deveria ser o resultado de uma "articulação de planos" (como pensavam tanto Pudovkin quanto Eisenstein): ela deveria resultar da pressão do tempo dentro do mesmo plano. Revendo In the mood for love, vêm-me à mente antes de tudo essa definição poética do cineasta russo. Pois a imagem que fica na memória de quem viu esse filme é aquela de momentos de um tempo puro, em que se admira uma "bolha de tempo" (Jousse, 2006:30) flutuando entre os objetos e pessoas que a câmera recorta: os belos quadris de Maggie Cheung, sob um vestido colado, andando em câmera lenta, uma coluna de cigarro pairando no ar noturno da redação de um jornal, um casal andando à noite numa rua deserta, pessoas atravessando corredores e descendo escadas, a chuva oblíqua caindo ao lado de uma lâmpada incandescente numa esquina deserta.

Antes mesmo de dar nomes a personagens, de pensar num enredo, de, tecnicamente, decupar/analisar uma cena, queria pensar que nesse e em outros filmes de Wong Kar Wai o essencial está na sua ambiência, ${ }^{1}$ naquilo que Hans Ulrich Gumbrecht (2010) chama de Stimmung: algo que se produz de forma disseminada e simultânea em uma determinada situação, mas ainda se mantendo, paradoxalmente, indefinível. O que Gumbrecht (alemão radicado nos EUA) tenta traduzir pela aproximação de duas palavras inglesas, "climate" e "mood": ambas remetem a uma certa atmosfera, que pode estar diluída e imperceptível em uma situação ou num texto, um 
certo "ar", como aquele que se percebe em momentos de desespero ou de melancolia.

Como historiador e crítico cultural, Gumbrecht está interessado em criar mecanismos que permitam "ler" a dimensão material da Stimmung, o modo como ela produz presença. O termo "mood" define a Stimmung como "um sentimento íntimo tão privado, que, para sua definição, não se encontram facilmente conceitos adequados" (Gumbrecht, 2010:10). Já como "climate", a Stimmung corresponde a algo de objetivo, uma dada disposição que pode ter uma determinada influência física sobre indivíduos e grupos. Uma Stimmung pode ser, pois, localizável em diferentes camadas culturais de uma época, como o "tom" de uma presença material, como uma atmosfera, que define a relação de um texto com o seu ambiente. Ler a(s) ambiência(s) de um texto significa, pois, entendê-lo não como alegoria de um tempo histórico, mas buscar a concretude de seu timbre no presente da leitura (resgatando a "produção de presença" que o texto institui), pois é sempre a leitura que desperta o texto de seu adormecimento nos infinitos arquivos da História.

O título In the mood for love nada tem a ver com o título original, em cantonês, do filme: "fa yeung nin wa", algo próximo a "os anos floridos". Segundo depoimentos de Wong Kar Wai (2013), o título ocidental do filme se originou da canção In the mood for love de Brian Ferry. Não se tratava, segundo ele, de um filme sobre o amor, mas sobre o "mood for love", então o título lhe pareceu perfeito. Se voltarmos à canção de Brian Ferry, veremos que a ambiência (termo que passo a usar para Stimmung) do filme está toda lá: primeiro, o ritmo percussivo e os pizzicatos de violino, típicos dos boleros dos anos 50, com um acordeão arrastando longas notas de tango, enquanto a voz melancólica de Ferry decanta a sensualidade e o erotismo da "disposição" de amar provocada pela mera proximidade 
dos corpos: "I'm in the mood for love / simply because youre near me". Essa é uma das características mais marcantes do cinema de Kar Wai, conseguir traduzir esse leque de sensações que surgem no instante da aproximação, antes que as coisas realmente aconteçam. Não é, pois, a sucessão de acontecimentos, as causas e efeitos das ações humanas, mas os interstícios e as brechas entre os acontecimentos e as relações, $o$ que interessa filmar. É nessas brechas que florescem os afetos. Por isso a câmera, como um curioso, está sempre se escondendo atrás de janelas, batentes e cantos de parede, como se quisesse surpreender o momento exato em que brota uma lágrima, ou um suspiro. Como entender o segredo que alguém deixou escondido em um buraco, seguindo uma velha tradição de sussurrar um segredo num buraco cavado numa árvore, motivo que aparecerá em In the mood for love e em 2046.

Não por acaso, o método de filmagem de In The mood for love enlouqueceu a equipe, os produtores, e sobretudo os atores, acostumados a um roteiro. In the mood for love não tinha roteiro, não tinha história prévia. Numa entrevista aos Cahiers du Cinéma, a atriz Maggie Cheung relata o processo de filmagem: depois de alguns meses filmando, ela descobriu que Kar Wai não tinha um roteiro pronto, mas antes ia criando o filme a partir da visualização dos takes filmados; quanto mais ia filmando, mais a ideia do filme se adensava; isso dava-lhe o "tom" da atuação:

A acumulação do tempo de filmagem permitiu que eu me fundisse totalmente à personagem. Começamos a partir de nada. Eu não tinha roteiro, não tinha idéia do que o filme iria contar. O personagem deveria ser inteiramente construído. Durante quinze meses, ele formou-se lentamente. Um trabalho de aborção se produziu. (apud Jousse, 2006: 29) 
O trabalho de Kar Wai em In the mood for love, é, pois, muito mais o de um escritor, que o de um diretor: tateando no escuro, ele vai buscando um sentido à medida que sua narrativa se constrói. Logo, a trama em que estão envolvidos os personagens do filme não é muito diferente da trama em que o diretor envolve a sua equipe, e que pode ser entendida a partir de uma das canções-tema do filme: Quizás, Quizás, de Oswaldo Farrés, na voz de Nat King Cole:

Siempre que te pregunto

Que cuando, como y donde

Tu siempre me respondes

Quizás, quizás, quizás

Y asi pásan los dias

Y yo desesperado

Y tu, tu contestando

Quizás, quizás, quizás.

O indecidível da canção de Oswaldo Farrés constitui a forma de produção, que por sua vez afeta a situação amorosa do par Sr. Chow (Tony Leung) e Sra. Chan (Maggie Cheung): ambos foram traídos pelos respectivos esposa e marido, e agora tentam vingar-se (ou aplacar a dor) flertando. Existe uma geometria de indecidibilidade na estrutura do filme: dados os pares $\mathrm{AB}$ e $\mathrm{CD}$, se A e D se combinam, logo $\mathrm{B}$ e $\mathrm{C}$ devem constituir um novo par. Mas a vida não é geométrica, apesar da simetria da situação (ou, como diz Paulinho da Viola, "a vida, meu caro, não é uma equação"). A mesma força que atrai A e D repele $\mathrm{B}$ e $\mathrm{C}$, que são como imãs que se aproximam pelo lado oposto. Contudo, à medida que se aproximam, a mesma força que os afastava (o ciúme dos seus respectivos cônjuges) vai servir para criar entre eles uma relação de proximidade cada vez mais intensa. Para desespero 
ou gozo do espectador, Kar Wai decide omitir uma solução final, já que desde o modo como filmava, parecia estar menos interessado no desenlace, e mais no desenvolvimento da trama.

Se tivéssemos que descrever a armação retórica da narrativa de In the mood for love, chegaríamos a algo como: uma apresentação inicial nos revela pouco a pouco a traição, os encontros do Sr. Chan com a Sra. Chow, que, aliás, nunca são mostrados diretamente, mas sempre no espaço do fora-de-campo: ouvimos suas vozes, vemos fragmentos de seus corpos, supomos sua presença. O essencial desse momento é o "pouco a pouco". A cenografia (de William Chang, aliás, também montador e figurinista) e a fotografia (de Cristopher Doyle) também se unem para criar uma geografia confusa (por um mesmo corredor vemos passar os personagens, que moram em quartos vizinhos), e, por que não, barroca (a música de Michael Galasso contribui muito para isso); a câmera quase sempre enquadra os atores a partir de portas, batentes e janelas, criando uma sensação de claustrofobia, quase como se pudéssemos imaginar os personagens dentro de um labirinto.

Passada essa apresentação, na qual se enfatiza o cotidiano e o banal (os personagens passam o tempo jogando Ma-Jong, comendo macarrão, datilografando ou fumando), veremos o Sr. Chow e a Sra. Chan se aproximarem: eles passam a se encontrar em restaurantes, nos quais desfiam o novelo da traição, enquanto saboreiam comidas ocidentais; vemo-los também em um hotel, onde simulam para si próprios como teria sido a traição; finalmente no próprio quarto de Chow, a pretexto de escreverem uma novela de artes marciais. A princípio, une-os meramente o desejo de descobrir a traição; em seguida, compartilham o interesse por histórias de artes marciais, até que o Sr. Chow passa a escrever, com a ajuda da Sra. Chan, suas próprias histórias (em 2046, o mesmo personagem já se dedicará 
inteiramente aos livros de artes marciais, que também é o tema de Ashes of Time, também protagonizado por Tony Leung e Maggie Cheung, e do recente The grandmaster). Dessa experiência de escrita surge um amor cada vez mais intenso, que os leva a um novo impasse: estariam eles cometendo o mesmo erro dos seus respectivos? Não seria eticamente condenável também aquele amor que nasceu entre eles? Afinal, uma nova geometria de indecidibilidade cria uma situação que se arrasta ao longo de todo o desenvolvimento da narrativa.

No que se pode chamar de desfecho do filme, o Sr. Chow parte, sozinho, para Cingapura (tal como acontece com os personagens principais de Days of being Wild, ambientado no final dos anos 50), e passam-se cinco anos. Quando retorna a Hong-Kong e à casa onde viveram, é informado de que todos os moradores antigos se mudaram, e que apenas vive ali uma senhora com uma criança. Logo depois, vemos a mesma Sra. Chan vir à casa onde viveu, com uma criança. E o filme acaba com uma sequência em que o Sr. Chow guarda seu segredo num buraco escavado numa parede do templo de Angkor, no Camboja.

Poucos instantes antes do fim, a passagem do tempo de separação do Sr. Chow e da Sra. Chan será marcada pela inserção de um filme documental da visita de Charles De Gaulle ao Camboja. Esse fragmento de história real num filme que trata de questões afetivas pode parecer um mero acaso, uma mera marca identificatória do tempo na narrativa. Mas lembremos que a visita de De Gaulle marca o fim do processo colonialista europeu na Ásia. Wong Kar Wai nasceu em Shangai, mas foi criado em Hong-Kong, um dos últimos protetorados britânicos na Ásia. A maior parte de seus filmes tenta reconstruir a história de um tempo em que Hong-Kong viveu uma forte influência ocidental. Não é por acaso que os mambos de Xavier 
Cougat (que vinham através das filipinas, colônia espanhola), músicas de Dean Martin, tangos e costumes ocidentais povoam os filmes de Kar Wai. A questão do processo colonial e da ocidentalização está sempre colocada. Inclusive em 2046: a pretexto de ser apenas uma ficção científica melodramática que acontece em 2046 (mas também uma referência ao número do quarto de hotel de In the mood for love em que a Sra. Chan e o Sr. Chow se encontram), a data de 2046 também é aquela em que Hong-Kong deveria ser definitivamente anexada à República da China.

Queremos dizer que, de alguma forma, a História está inscrita nos filmes de Kar Wai de forma indelével e não-fortuita. Não é casual que ele tenha insistido em voltar aos anos 50/60, época banhada ainda pelas luzes obscuras do colonianismo. A visão nostálgica de um passado de sofrimento e dor está de alguma forma inscrita nas tramas melodramáticas vividas pelos personagens (tal como a brutalidade da invasão japonesa se inscreve no percurso pessoal dos lutadores de Kung Fu em The Grandmaster). Mas pode ser que, passados muitos e muitos anos, quando já houverem sido apagadas todas as marcas daquele período histórico específico, ou quando poucos souberem ler essas marcas, o espectador de filmes como Days of being wild, In the mood for love e 2046 seja apenas o cidadão comum que vai assistir a um filme sem saber muito bem onde ele foi feito, por que foi feito, mas, ainda assim, sai da sala com vontade de mudar de vida, e quem sabe, de mudar o mundo. Talvez porque, mais do que registrar meramente a História, em seu desfilar de mil acontecimentos aleatórios e enfadonhos, o diretor de tais filmes foi capaz de capturar a bolha delicada e irisada que encerra uma ambiência, essa "realidade escondida" de um tempo. 


\section{Nota}

1. Devo algumas considerações sobre o conceito de ambiência e seu emprego ao meu orientando de doutorado Alex Sandro Martoni (UFF/ Stanford).

\section{Referências}

GUMBRECHT, Hans Ulrich. Stimmungen lesen: über eine versteckte Wirklichkeit der Literatur. München: Hanser Verlag, 2011.

KAR WAI, Wong. In the mood for love. Hong-Kong, 2012. [Blu-ray: The Criterium Collection, 2012].

KAR WAI, Wong. "In the mood for love". Wikipedia. Acesso em 10.08.2013. Disponível em http://en.wikipedia.org/wiki/In_the_Mood_for_Love.

JOUSSE, Thierry. Wong Kar-wai. Paris: Cahiers du Cinéma/CNDP, 2006.

TARKOVSKI, Andrei. Esculpir o tempo. São Paulo: Martins Fontes, 1989.

(Recebido em 03/09/2013. Aprovado em 19/11/2013) 
